\title{
Advances in Observation and Estimation of Land Use Impacts on Climate Changes: Improved Data, Upgraded Models, and Case Studies
}

\author{
R. B. Singh ${ }^{1}$ and Chenchen Shi $^{2}$ \\ ${ }^{1}$ Department of Geography, Delhi School of Economics, University of Delhi, Delhi 110007, India \\ ${ }^{2}$ State Key Laboratory of Water Environment Simulation, School of Environment, Beijing Normal University, Beijing 100875, China \\ Correspondence should be addressed to R. B. Singh; rbsgeo@hotmail.com
}

Received 28 August 2013; Revised 15 December 2013; Accepted 18 December 2013; Published 12 January 2014

Academic Editor: Burak Güneralp

Copyright ( 2014 R. B. Singh and C. Shi. This is an open access article distributed under the Creative Commons Attribution License, which permits unrestricted use, distribution, and reproduction in any medium, provided the original work is properly cited.

Global land use and land cover pattern has greatly changed in the past 50 years, which exerts direct or indirect influence on the climate change remarkably at both regional and global scales. Therefore, observing and estimating the land use impacts on surface climate is essential and has been continuously promoted by researchers. This paper explores the advancement in the models, data, and application for observing and estimating the land use impacts on surface climate and points out further research needs and priorities, which hopefully will provide some references for related studies.

\section{Introduction}

The study of land use and land cover change (LUCC) and its impact on climate is of great significance [1]. There have been tremendous changes in the global land use pattern in the past 50 years, which have enormous influence on the global climate change. Quantitative analysis for the impacts of LUCC on surface climate is one of the core scientific issues to understand the influence of human activities on global climate. For instance, the diverse role of LUCC on precipitation has been documented and land conversion continues at a rapid pace, making this type of human induced disturbances of the climate system continue and become even more significant [2]. The review paper of Deng et al. [1] comprehensively analyzed the primary scientific issues about the impacts of LUCC on the regional climate and reviewed the progress in relevant researches. Earlier as there was no systematic review paper, Deng et al. reviewed the systematic modeling of impacts of LUCC on regional climate for the first time. This paper further develops a systematic review to cover the advances in this research field, in which the improved data, upgraded models, and case studies in observation and estimation of land use impacts on climate changes have been introduced.

\section{Advancement in LUCC Dataset}

2.1. Previous Dataset. LUCC has been recognized as a key component in global environmental change. It was not until the last twenty years that land cover products were applied to most of the climate models. These products were initially compiled from maps, ground surveys, and various national statistical sources, which have inherent limitations [3-5]. In the mid-1990s, global-scale land cover products generated from remote sensing images became available. Various land cover datasets were usually classified from remote sensing images, including MSS/TM/ETM+, SPOT, and MODIS, which have been used in numerous climate modeling studies at regional to global scales. Since the 1990s, a series of land use/land cover datasets have been produced in many international institutes and countries, such as Global Land Cover Characteristics (GLCC) [6], University of Maryland (UMD) Global Land Cover Facility (GLCF) land cover dataset [7], and Olson Global Ecosystem (OGE) 
dataset $[8,9]$. These products were interpreted artificially with computer aids and then verified by systematic field survey. The need of land use/cover dataset with high accuracy for the climate simulation has been recognized widely in the climate modeling community [10]. Some research showed that the result of the regional precipitation study would be greatly influenced if the accuracy of land cover data is under $80 \%$, and the result may get progressively worse as the accuracy continues to decrease [11]. Therefore the accuracy of the land cover data is of crucial importance to the climate studies. For example, in India and China, large amounts of land cover data have been produced in recent years using the remote sensing data [12]. Unfortunately, neither the overall nor class-specific accuracy of most datasets was able to meet the common requirements of the regional climate modeling.

The disagreement and low accuracy among these land cover datasets primarily resulted from the differences in the sensors, spatial resolutions, algorithms, and classification schemes [13]. Moreover, most of the land cover datasets derived from remote sensing are not $100 \%$ accurate. A new statistical measure $\mathrm{Q}$ was developed to evaluate land cover datasets in land-climate interaction research, which calculates biophysical precision of land cover datasets using $1 \mathrm{~km}$ monthly MODIS Leaf Area Index (LAI) product [14]. The spatial data mining is proposed to produce a higher accuracy land cover map, whose classification system should be compatible with the well accepted classification system used in regional climate simulations $[12,15]$.

\subsection{Classification of LUCC Data for Climate Models. There} are a number of schemes that have been proposed for regional to global-scale land cover categorization, including the International Geosphere-Biosphere Programme (IGBP)Data and Information Systems: Land Cover Working Group developed land cover categorization scheme [16], a sixclass biome categorization [17], the Simple Biosphere Model scheme [18], and the Federal Geographic Data Committee vegetation characterization and information standards [19]. Many parameters in a land surface model are identified based on the land cover types, for instance, time-invariant model variables (e.g., vegetation reflectance, canopy top height, canopy base height, root depth, and leaf respiration factor) in the Simple Biosphere Model 2 (SIB2) [18] and the Common Land Model (CoLM) [20]. Thus, the specific land cover classification units should not only be discernible (and with high accuracy) from remote sensing image and ancillary data but also be directly related to the physical characteristics of land surface. The IGBP scheme embraces the same philosophy but with modifications to be compatible with existing schemes used by environmental modelers, to incorporate land use in addition to land cover and to represent mosaics [16].

In order to enhance the LUCC study, data need to be updated to increase the accuracy. The temporal land cover datasets have been widely used in numerous climate simulation projects. Most attention has been paid to effects of the accuracy of the land cover data on the climate simulation. Though there are temporal land use data with accuracy higher than $90 \%$ [15], still the high-precision land cover data is absent. Therefore, there is an urgent need to reclassify the LUCC dataset to feed into the General Circulation Model (GCM) and Regional Climate Model (RCM). For example, in a case study on North China, Wu et al. [15] overlaid the land cover maps of the IGBP-DIS, Global Land Cover 2000 (GLC), UMD Data, and Data Center for West China (WESTDC), and the compatible grids with classification were selected as the sample grids. They combine the land cover data with the land use data to generate land cover data of high accuracy for the climate simulation. Their study showed that the C4.5 algorithm was suitable for converting the land use data to land cover data of IGBP classification. The temporal land cover data produced by their method can meet the accuracy requirement of the climate simulation and can be used as the parameter of dynamical downscaling in regional climate simulation, which constitutes a significant improvement in the data processing.

2.3. Data Resolution and Reliability. Land surface has considerable heterogeneity because of the existence of different land cover types such as bare surface, water bodies, urban land, trees, and snow/ice, which vary over small distance. This surface variability not only determines the microclimate but also affects mesoscale atmospheric circulation [21-23]. The accurate land cover maps are the foundation for land surface, ecological and hydrological modeling, carbon and water cycle studies, and research on global climate change $[24,25]$. With many land cover products from different sources becoming available for a given region of the Earth, a challenge arises as to which product is optimal for a landclimate modeling study. Traditional classification accuracy assessment is primarily dependent on ground-based surveys or interpretation of high spatial resolution aerial photos and satellite images. By comparing the classified land cover dataset with the ground-truthing data, error metrics can be developed to report the commission and omission errors. Measures of accuracy, such as the Kappa coefficient of agreement, are frequently calculated to express classification accuracy $[26,27]$. Therefore, the researcher should take full advantage of geographic knowledge in the GIS database to support classification, thus to remarkably enhance the classification accuracy of land cover.

Accurate representation of land surfaces is an important factor for climate modeling. However, little attention has been paid to the effect of land cover classification accuracy on climate simulations. In reality, land cover accuracy rarely obtains the commonly recommended $85 \%$ target [10]. The accuracy of land use classification can reach $73 \%-77 \%$ using decision-tree classification methods and thereby increasing mapping efficiency by $50 \%$ [28]. In addition, most assessments of classified accuracy were conducted using the same dataset as was used to train the classifier. Therefore, the classified accuracy was overstated. Moreover, the spatial data mining techniques for the land cover classification is applied. Finally, the evaluation of the accuracy and uncertainty of the land cover data is accomplished by different methods; the accuracy could reach $88.62 \%$ [15]. Inaccurate representation of land cover will lead to differences in simulating 
sensible heat flux, latent heat flux, and many other variables depending on vegetation and land use parameters. Remote sensing provides accurate representation of Earth's surface on different spatial and temporal scales and is an attractive source for creating high accuracy land cover data. Therefore, it is feasible to take advantage of the existing land cover data from different sources to make a high accuracy land cover data using the spatial data mining method. The information fusion strategy is proposed to produce a higher accuracy land cover map of China [29], whose classification system should be compatible with the well accepted classification system used in land surface modeling.

\section{Upgraded Models}

Studies on LUCC processes are often challenged by the complex nature and unexpected behavior of both human drivers and natural constraints. Therefore, a land use change dynamic model was needed to simulate the interdependencies and feedback mechanisms between social, economic, and ecosystem environments. Land use change emerges from the interactions among various components of the coupled human-landscape system, which then feeds back to the subsequent development of those interactions [30]. Currently, there are a lot of evaluation models to simulate the dynamic decision and spatiotemporal process of land use change [1].

\subsection{Current Models}

3.1.1. Empirical Statistical Model. There are numerous empirical statistical models applied to land system dynamics simulation [31,32]. The empirical statistical model can provide the information of the key driving forces of land use change and reflect the time lag effect of response. Moreover, the data input could be multiscaled. However, certain deficiencies exist in this kind of model, as the model requires to be driven by the data of exogenous land use change rate and amount. Besides, the conversion rule of land use should be manually set. Therefore, the model could not provide references for other regions except for the selected study area.

3.1.2. Econometric Model. The econometric model is a policy evaluation model based on sustainable utilization of land utility which can evaluate the influence of policy factors on land use and promote multifunction sustainable utilization of land.

Sustainability Impact Assessment. Tools for Environmental, Social, and Economic Effects on Multifunctional Land Use in European Regions (SENSOR) is funded by the European Commission FP6 framework research programme to develop tools for ex-ante impact assessment of European policies related to rural land use [33]. It includes a detailed macroeconometric model called NEMESIS, which models cross sector impacts, being the major characteristic of SENSOR project [34]. As it applies a cross-sector approach to land use, it is suitable for large regions. The Dynamics of Land
System (DLS) model as another representative econometric model can realize the dynamic simulation of land system on the fine-grid scale through the analysis of land use allocation constraints and simulation of land supply and demand balance. Several case studies show that DLS is able to measure the influence of natural and socioeconomic driving factors to predict the future LUCC, which could provide meaningful decision making for informed land use planning and management [35].

3.1.3. Agent-Based Model (ABM). Since the 1990s, with the rapid development of computational power, a number of models based on ABM began to be applied in LUCC research, and models based on agent land use/land cover change (ABM/LUCC) have been gradually developed [36]. The agent based model has high flexibility, but the flexibility of the model increases the uncertainty of the model and thus bringing the difficulties for the model validation. The agent based model strives to simulate the individual and group behavior together with decision making model, but the individual decision-making behavior possesses great complexity. Zhang et al. adopted this model in analyzing the impacts of climate change and agents' adaptive behaviors on the regional land use changes [37]. In addition, their research showed that the model is sensitive to the climatic conditions, which gave credit to ABM on modeling the LUCC impact on climate.

3.1.4. Coupled Econometric and ABM Model. The combination of agent based model and the econometric model can simulate complex decision problem of land use in better way, so as to provide new methods for simulation of land use dynamics.

The agent model and the econometric model of coupling in the areas of land use will get recognition and application in the future, mainly embodied in the following two aspects: the combination of the agent based model and the econometric model can simulate the individual and group decision behavior considering the interaction among the micro- and macrodecisions at the same time.

The integration of the economic and agent based model combines the process of social and economic factors with the land use dynamics. The comprehensive model not only can be used in the simple scenario simulation of land use but also can be used in complex scenario. The two models, interconnected and interdependent, constitute a complex system with hierarchical heterogeneity.

Among recent studies on land use models, Deng et al. introduced a land use change dynamic (LUCD) model embedded in RCM [38]. The Agro-ecological Zone (AEZ) model is intended as the optimal option for constructing one of the constituent modules, which is naturally correlated with AEZs. The agent-based module identifies the land use change demand and vegetation change can be realized and provides the land use change simulation results which are the underlying surfaces needed by RCM. By importing the RCM's simulation results of climate change and providing the simulation results of land use change for RCM, the LUCD model can be embedded in RCM. The coupled simulation 
system of LUCD and RCM will be extraordinarily powerful in land surface system simulation. The innovation of their study lies in that current research could only simulate the land cover change through vegetation change modeled in RCM and GCM but not the land use change. But this study simulated dynamic change of land use, which is a great breakthrough in systematically reporting the land use change.

3.2. Scenario Development. Scenario analysis of land use change and dynamic prediction involves many driving factors that affect land use change, which has always been the attention of academia worldwide. Through simulating regional land use change under different scenarios, rational forecasting and evaluation of the future land use could be made, which will offer scientific reference for regional and national scale land use planning and management.

Climate scenarios are plausible representations of future climate conditions, which can be produced using a variety of approaches, and among which, regional climate models are increasingly popular [39]. There is a notable increase in interest in regional-scale climate scenarios and projection methods, especially for impact and adaptation assessment [40].

The Intergovernmental Panel on Climate Change (IPCC) has been working on the scenarios of potential future anthropogenic climate change, the underlying driving forces, and the response options. According to IPCC [41, 42], socioeconomic scenarios could facilitate the exploration of long term consequences of anthropogenic climate change and available response options. The socioeconomic futures in the scenario consist of qualitative narrative descriptions of future trends and quantitative assumptions (also called the storyline) about key socioeconomic variables.

In the study of land use impact on climate, with a good database, an appropriate method shall be adopted to facilitate the study, and the scenario analysis can be adopted here, which performs macrostructure change. In the study of $\mathrm{Xu}$ et al. [43], three kinds of scenarios were designed based on the socioeconomic development. They simulated land use trends under three different scenarios including baseline scenario and two control scenarios (risk scenario and rapid development mode transformation scenario) and obtained the most suitable scenario to control the $\mathrm{CO}_{2}$ emissions of the three scenarios. Their scenarios excel other scenarios as they compile the IPCC scenario with the specific situation in the research area. With the scenario analysis, it will be possible to provide a theoretical basis for the future land use planning in adaptation to climate change. As the first attempt of the systematic analysis of LUCC scenarios and with the dataset produced by their study, their research laid a good foundation for future researches.

\section{Land Use Impacts on Climate Changes: Case Studies}

With an improved database and models, the climate effect model shall be introduced in order to apply the simulation platform of the land use impact on the climate. Climate change simulation has increased in many countries like China during recent years. Many scholars offered representative methods; among them, Gao et al. simulated the climate change in China using the Abdus Salam International Centre for Theoretical Physics (ICTP) Regional Climate Model version 3 (RegCM3) [44]. The RegCM3 can reproduce the observed spatial structure of surface air temperature and precipitation. However, so far RegCM3 is a hydrostatic model which limits the further increase of its resolution beyond $\sim 10 \mathrm{~km}$ [45]. Wu and $\mathrm{Fu}$ used a linear fitting method to estimate the change of precipitation intensity spectra at different spatial scales in China [46].

As a study on climate effect, the Weather Research and Forecasting (WRF) Model could be correlated. Qu et al. [47] used WRF to explore the impacts of land cover change on the near-surface temperature in a research in Northern Plain in China. They tested and verified the ability of the WRF to simulate the near-surface temperature in the North China Plain. Notably, in this study the LUCC dynamic model and LUCC reclassification were also applied to form a good systematic modeling of LUCC. Coupled with WRF Model, land use impact on climate was well simulated.

Based on the compiled climate model, the climate change influence on climate index could be further explored. Zhang et al. [48] first reported the climate impact on grassland. Their study took a macro and mesoscale analysis of the possible changing trends of the net primary productivity (NPP) of local grasslands under four RCPs scenarios. The results showed that the grassland productivity will be greatly influenced by the fluctuations of precipitation and temperature.

With the above mentioned studies, LUCC and future climatic scenarios simulation in particular areas were conducted. Simulation of LUCC and its climatic effects were integrated through linking the functions of the newly developed models with those of the existing models.

Further, studies related to land use changes associated with climate variations were promoted with the advances in the research methods. Deng et al. [49] conducted a revisit to the impact of land use changes on the human well-being via altering the ecosystem provisioning services. LUCC and climate change exert tremendous influence on ecosystem provisioning services by changing agro-ecosystem services functions and forest and/or grassland ecosystem services functions. In order to tackle the ecosystem provisioning services problems, measures were taken, which increased the input and reduced the outcome, at the same time augmented the health risk and harm to human well-being.

R. B. Singh and S. Singh [50] have employed pixel based high resolution mapping and modeling at small scale land use pattern and land cover analysis to identify induced flood risks in the Yamuna and the Hindon basin area by WetSPA Model. Flood forecasting has been done with the help of ILWIS Model while LUCC has been analyzed with the help of SRTM, IKNOS, and Landsat data to find out that almost 36\% forest land has been transformed into settlement and other land uses. Yamashima et al. [51] have analyzed the impact of historical LUCC on the seasonal cycle of hydroclimate over the Indian subcontinent and southern 
China. They investigated using a general circulation model MIROC3.2 coupling with land surface model MATSIRO over the period 1700-1850. A decrease in evapotranspiration has been observed over the Indian subcontinent due to decrease in precipitation which is induced by changes in land use/ cover.

Sahu et al. [52] have investigated the impact of recently invented global climatic variability modes like Indian Ocean Dipole (IOD) and El Niño Modoki at the regional climate scale particularly at the river catchment level on daily time series and concluded that at the upper river catchment climate variability has significant impact on seasonal stream flows and land use pattern. Sen Roy et al. [53] also conducted a comprehensive study to understand the spatial pattern of Urban Heat Islands (UHI) development within the rapidly changing urban landscape of Delhi metropolitan region and Kolkata metropolitan region [54]. In both the studies land use has been a key driving force for change in microclimate. In Delhi, overall higher temperatures were observed in the northern and western section, which constitute the most densely built-up residential areas and thereby experiencing rapid vegetation loss and land use change. Remote sensing and GIS based tools have been effectively used to predict UHI risks.

Recently, satellite meteorology products and applications get more and more importance. However, it cannot replace surface measurements. For example, satellite data in the form of GCMs needs observed data for model validation and improves the quality of statistical and scientific significances in research methods. Therefore, increasing emphasis should be given to integrate observed and simulated datasets for improving understanding about land use impacts on climate change $[55,56]$.

\section{Concluding Remarks}

This paper reviewed the progress of the research in observing and estimating the land use impacts on surface climate from the perspective of the improved models, enhanced data, and widely expanded applications. The major findings include the following: the reclassification of the temporal land cover data can meet the accuracy requirement of the climate simulation and can be used as the parameters of dynamical downscaling in regional climate simulation, which enhances the data processing and lays a good foundation for LUCC simulation. The Land Use Change Dynamics Model compatible with RCMs is a great breakthrough in systematically reporting the dynamic change of land use. The scenario analysis performed the macrostructure change, which facilitated the study of land use impact on climate. LUCC dynamic model and LUCC reclassification can be applied to form a good systematic modeling of LUCC coupled with the WRF Model; land use impact on climate was well simulated.

Despite the progresses in the research, there are still some research needs, which should be further addressed. For example, the LUCC parameters need to be precisely expressed to make sure of the accuracy of the simulation. It is necessary to strengthen the observation of the land surface processes due to the variations in the impact of land use change on climate.

The researches observing and estimating land use impact on climate should mainly focus on two aspects [1]: (i) exploring the climate effects of the future LUCC as the current study has mainly been addressed on the past and current LUCC and (ii) predicting the land use changes in the future and assessing its influence on the future climate.

\section{Conflict of Interests}

The authors declare that there is no conflict of interests regarding the publication of this paper.

\section{Acknowledgments}

This research was financially supported by the National Key Programme for Developing Basic Science in China (Grant no. 2010CB950900), the major research plan of the National Natural Science Foundation of China (Grant no. 91325302), and the National Natural Science Funds of China for Distinguished Young Scholar (Grant no. 71225005).

\section{References}

[1] X. Deng, C. Zhao, and H. Yan, "Systematic modeling of impacts of land use and land cover changes on regional climate: a review," Advances in Meteorology, vol. 2013, Article ID 317678, 11 pages, 2013.

[2] R. A. Pielke, J. Adegoke, A. Beltrán-Przekurat et al., "An overview of regional land-use and land-cover impacts on rainfall," Tellus, Series B, vol. 59, no. 3, pp. 587-601, 2007.

[3] E. Matthews, "Global vegetation and land use: new high-resolution data bases for climate studies," Journal of Climate \& Applied Meteorology, vol. 22, no. 3, pp. 474-487, 1983.

[4] J. S. Olson, J. A. Watts, and L. J. Allison, "Carbon in live vegetation of major word ecosystems," Tech. Rep. ORNL-5862, Oak Ridge National Laboratory, Oak Ridge, Tenn, USA, 1983.

[5] J. Cihlar, "Land cover mapping of large areas from satellites: status and research priorities," International Journal of Remote Sensing, vol. 21, no. 6-7, pp. 1093-1114, 2000.

[6] T. R. Loveland, B. C. Reed, J. F. Brown et al., "Development of a global land cover characteristics database and IGBP DISCover from $1 \mathrm{~km}$ AVHRR data," International Journal of Remote Sensing, vol. 21, no. 6-7, pp. 1303-1330, 2000.

[7] M. C. Hansen and B. Reed, "A comparison of the IGBP DISCover and University of Maryland $1 \mathrm{~km}$ global land cover products," International Journal of Remote Sensing, vol. 21, no. 6-7, pp. 1365-1373, 2000.

[8] J. Olson, "Global ecosystem framework-definitions," USGS EROS Data Center Internal Report, Sioux Falls, SD, vol. 37, 1994.

[9] J. Olson, "Global ecosystem framework-translation strategy," USGS EROS Data Center Internal Report, Sioux Falls, SD, vol. 39, 1994.

[10] J. Ge, J. Qi, B. M. Lofgren, N. Moore, N. Torbick, and J. M. Olson, "Impacts of land use/cover classification accuracy on regional climate simulations," Journal of Geophysical Research D, vol. 112, no. 5, Article ID D05107, 2007. 
[11] J. J. Feddema, K. W. Oleson, G. B. Bonan et al., "Atmospheric science: the importance of land-cover change in simulating future climates," Science, vol. 310, no. 5754, pp. 1674-1678, 2005.

[12] Y. H. Ran, X. Li, L. Lu, and Z. Y. Li, "Large-scale land cover mapping with the integration of multi-source information based on the Dempster-Shafer theory," International Journal of Geographical Information Science, vol. 26, no. 1, pp. 169-191, 2012.

[13] M. Herold, P. Mayaux, C. E. Woodcock, A. Baccini, and C. Schmullius, "Some challenges in global land cover mapping: an assessment of agreement and accuracy in existing $1 \mathrm{~km}$ datasets," Remote Sensing of Environment, vol. 112, no. 5, pp. 2538-2556, 2008.

[14] J. Ge, N. Torbick, and J. Qi, "Biophysical evaluation of landcover products for land-climate modeling," Earth Interactions, vol. 13, no. 6, 2009.

[15] F. Wu, J. Zhan, H. Yan, C. Shi, and J. Huang, "Land cover mapping based on multisource spatial data mining approach for climate simulation: a case study in the farming-pastoral ecotone of North China," Advances in Meteorology, vol. 2013, Article ID 520803, 12 pages, 2013.

[16] A. Belward and T. Loveland, "The IGBP DIS $1 \mathrm{~km}$ land cover project: remote sensing in action," in Proceedings of the 21st Annual Conference of the Remote Sensing Society, pp. 1099-1106, Southampton, UK, 1995.

[17] S. W. Running, T. R. Loveland, and L. L. Pierce, "A vegetation classification logic based on remote sensing for use in global biogeochemical models," Ambio, vol. 23, no. 1, pp. 77-81, 1994.

[18] P. J. Sellers, S. O. Los, C. J. Tucker et al., "A revised land surface parameterization (SiB2) for atmospheric GCMs. Part II: the generation of global fields of terrestrial biophysical parameters from satellite data," Journal of Climate, vol. 9, no. 4, pp. 706-737, 1996.

[19] F. G. D. Committee, "Vegetation Subcommittee. 1997," FGDC Vegetation Classification and Information Standards, vol. 3, 1996.

[20] X. Dai, X. Zeng, and R. Dickinson, "The Common Land Model (CLM): technical documentation and user's guide," Georgia Institute of Technology, 2001.

[21] D. L. Hartmann, Global Physical Climatology, Academic Press, 1994.

[22] C. P. Weaver and R. Avissar, "Atmospheric disturbances caused by human modification of the landscape," Bulletin of the American Meteorological Society, vol. 82, no. 2, pp. 269-281, 2001.

[23] Z. L. Yang, Modeling Land Surface Processes in Short-Term Weather and Climate Studies, World Scientific Series on Meteorology of East Asia, 2004.

[24] I. G. Change, Report, 1990.

[25] P. J. Sellers, R. E. Dickinson, D. A. Randall et al., "Modeling the exchanges of energy, water, and carbon between continents and the atmosphere," Science, vol. 275, no. 5299, pp. 502-509, 1997.

[26] R. G. Congalton, "A review of assessing the accuracy of classifications of remotely sensed data," Remote Sensing of Environment, vol. 37, no. 1, pp. 35-46, 1991.

[27] G. M. Foody, "Status of land cover classification accuracy assessment," Remote Sensing of Environment, vol. 80, no. 1, pp. 185-201, 2002.

[28] C. Homer, C. Huang, L. Yang, B. Wylie, and M. Coan, "Development of a 2001 national land-cover database for the United States," Photogrammetric Engineering and Remote Sensing, vol. 70, no. 7, pp. 829-840, 2004.
[29] Y. Ran, X. Li, and L. Lu, "Evaluation of four remote sensing based land cover products over China," International Journal of Remote Sensing, vol. 31, no. 2, pp. 391-401, 2010.

[30] Q. B. Le, S. J. Park, P. L. G. Vlek, and A. B. Cremers, "LandUse Dynamic Simulator (LUDAS): a multi-agent system model for simulating spatio-temporal dynamics of coupled humanlandscape system. I. Structure and theoretical specification," Ecological Informatics, vol. 3, no. 2, pp. 135-153, 2008.

[31] P. H. Verburg, B. Eickhout, and H. Meijl, "A multi-scale, multimodel approach for analyzing the future dynamics of European land use," The Annals of Regional Science, vol. 42, no. 1, pp. 57-77, 2008.

[32] J. Y. Liu and X. Z. Deng, "Progress of the research methodologies on the temporal and spatial process of LUCC," Chinese Science Bulletin, vol. 55, no. 14, pp. 1354-1362, 2010.

[33] K. Helming, B. Konig, and K. Tscherning, "SENSOR first annual report (public part)," Management, vol. 30, no. 3, pp. 391-405, 2006.

[34] T. Jansson, M. Bakker, B. Boitier et al., "Cross sector land use modelling framework," in Sustainability Impact Assessment of Land Use Changes, pp. 159-180, Springer, 2008.

[35] X. Deng, Q. Jiang, J. Zhan, S. He, and Y. Lin, "Simulation on the dynamics of forest area changes in Northeast China," Journal of Geographical Sciences, vol. 20, no. 4, pp. 495-509, 2010.

[36] T. P. Evans and H. Kelley, "Multi-scale analysis of a household level agent-based model of landcover change," Journal of Environmental Management, vol. 72, no. 1-2, pp. 57-72, 2004.

[37] T. Zhang, J. Zhan, J. Huang, R. Yu, and C. Shi, "An Agentbased reasoning of impacts of regional climate changes on land use changes in the Three-River Headwaters Region of China," Advances in Meteorology, vol. 2013, Article ID 248194, 9 pages, 2013.

[38] X. Deng, J. Liu, Y. Lin, and C. Shi, "A framework for the land use change dynamics model compatible with RCMs," Advances in Meteorology, vol. 2013, Article ID 658941, 7 pages, 2013.

[39] R. H. Moss, J. A. Edmonds, K. A. Hibbard et al., "The next generation of scenarios for climate change research and assessment," Nature, vol. 463, no. 7282, pp. 747-756, 2010.

[40] S. Solomon, D. Qin, M. Manning et al., "The physical science basis," in Contribution of Working Group I to the Fourth Assessment Report of the Intergovernmental Panel on Climate Change, pp. 235-337, 2007.

[41] E. Kriegler, B. O'neill, S. Hallegatte et al., CIRED Working Paper DT/WP, 2010.

[42] N. Nakicenovic, J. Alcamo, G. Davis et al., Special Report on Emissions Scenarios: a special report of Working Group III of the Intergovernmental Panel on Climate Change, Pacific Northwest National Laboratory, Environmental Molecular Sciences Laboratory (US), Richland, Wash, USA, 2000.

[43] Q. Xu, Q. Jiang, K. Cao, X. Li, and X. Deng, "Scenariobased analysis on the structural change of land uses in China," Advances in Meteorology, vol. 2013, Article ID 919013, 12 pages, 2013.

[44] X. Gao, Y. Shi, D. Zhang, and F. Giorgi, "Climate change in China in the 21st century as simulated by a high resolution regional climate model," Chinese Science Bulletin, vol. 57, no. 10, pp. 1188-1195, 2012.

[45] J. Wu, X. Gao, F. Giorgi, Z. Chen, and D. Yu, "Climate effects of the three gorges reservoir as simulated by a high resolution double nested regional climate model," Quaternary International, vol. 282, pp. 27-36, 2012. 
[46] F. Wu and C. Fu, "Change of precipitation intensity spectra at different spatial scales under warming conditions," Chinese Science Bulletin, pp. 1-10, 2013.

[47] R. Qu, X. Cui, H. Yan, E. Ma, and J. Zhan, "Impacts of land cover change on the near-surface temperature in the North China Plain," Advances in Meteorology, vol. 2013, Article ID 409302, 12 pages, 2013.

[48] R. Zhang, Z. Li, Y. Yuan, Z. Li, and F. Yin, "Analyses on the changes of grazing capacity in the Three-River Headwaters Region of China under various climate change scenarios," Advances in Meteorology, vol. 2013, Article ID 951261, 9 pages, 2013.

[49] X. Deng, Z. Li, J. Huang, Q. Shi, and Y. Li, "A revisit to the impact of land use changes on the human well-being via altering the ecosystem provisioning services," Advances in Meteorology, vol. 2013, Article ID 907367, 8 pages, 2013.

[50] R. B. Singh and S. Singh, "Rapid urbanization and induced flood risk in Noida, India," Asian Geographer, vol. 28, no. 2, pp. 147169, 2011.

[51] R. Yamashima, K. Takata, J. Matsumoto, and T. Yasunari, "Numerical study of the impacts of land use/cover changes between 1700 and 1850 on the seasonal hydroclimate in monsoon Asia," Journal of the Meteorological Society of Japan, vol. 89, pp. 291-298, 2011.

[52] N. Sahu, S. K. Behera, Y. Yamashiki, K. Takara, and T. Yamagata, "IOD and ENSO impacts on the extreme stream-flows of Citarum river in Indonesia," Climate Dynamics, vol. 39, no. 78, pp. 1673-1680, 2012.

[53] S. Sen Roy, R. B. Singh, and M. Kumar, "An analysis of local spatial temperature patterns in the Delhi Metropolitan Area," Physical Geography, vol. 32, no. 2, pp. 114-138, 2011.

[54] R. B. Singh and R. Nath, "Remote sensing, GIS and micrometeorology for monitoring and predicting urban heat islands in Kolkata mega city," Annals of NAGI, vol. 32, no. 1, pp. 17-39, 2012.

[55] R. B. Singh, J. Fox, and Y. Himiyama, Eds., Land Use and Cover Change, Science Publishers, Enfield, Conn, USA, 2001.

[56] Y. Himiyama and I. Bicik, Eds., Land Use Changes in Selected Regions in the World, Hokkaido University of Education, 2012. 

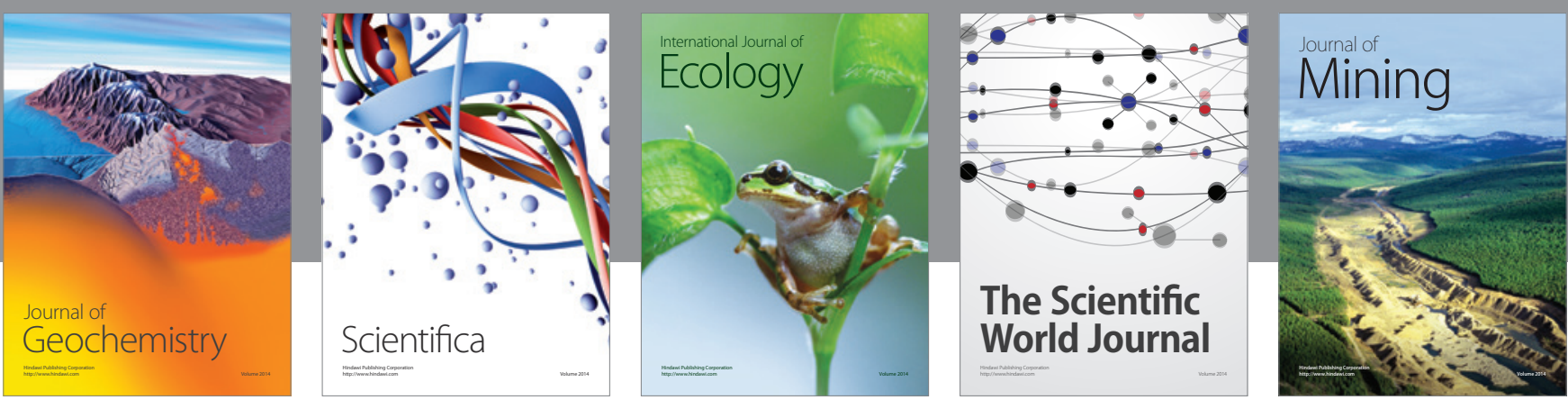

The Scientific World Journal
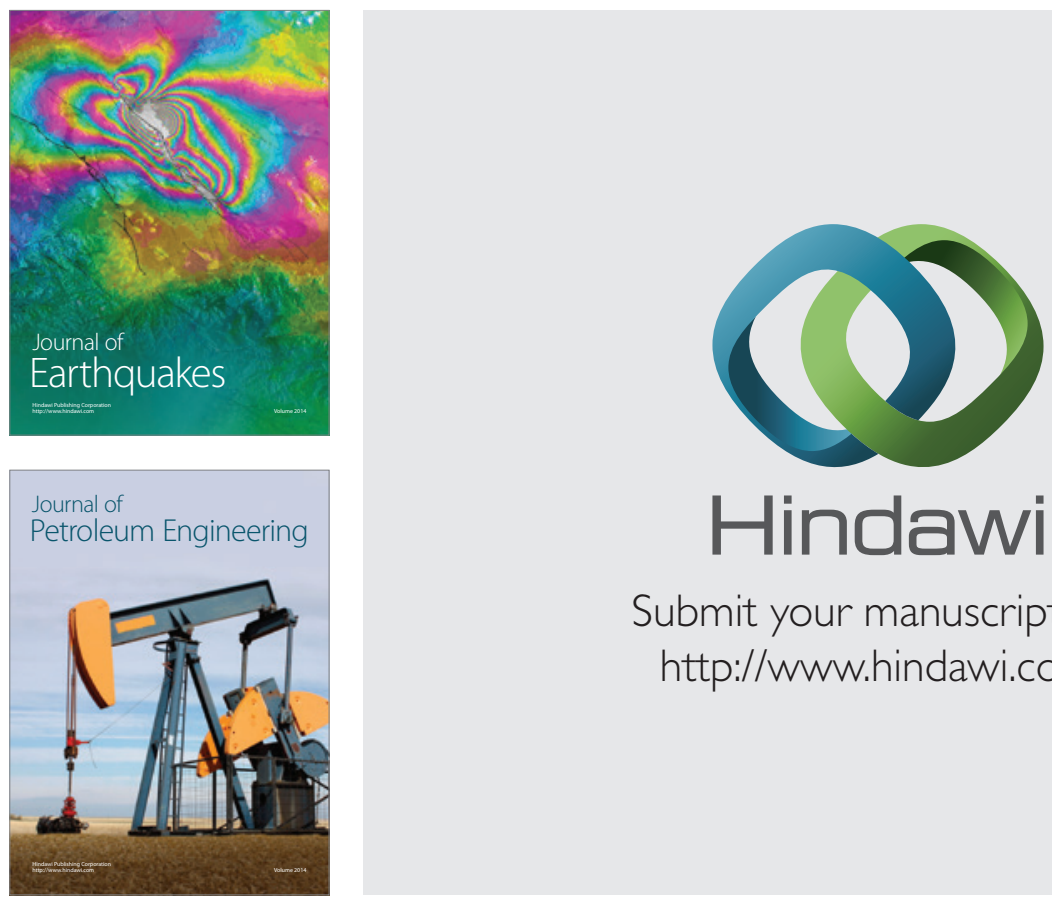

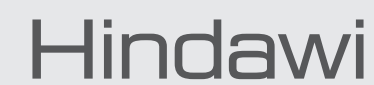

Submit your manuscripts at

http://www.hindawi.com
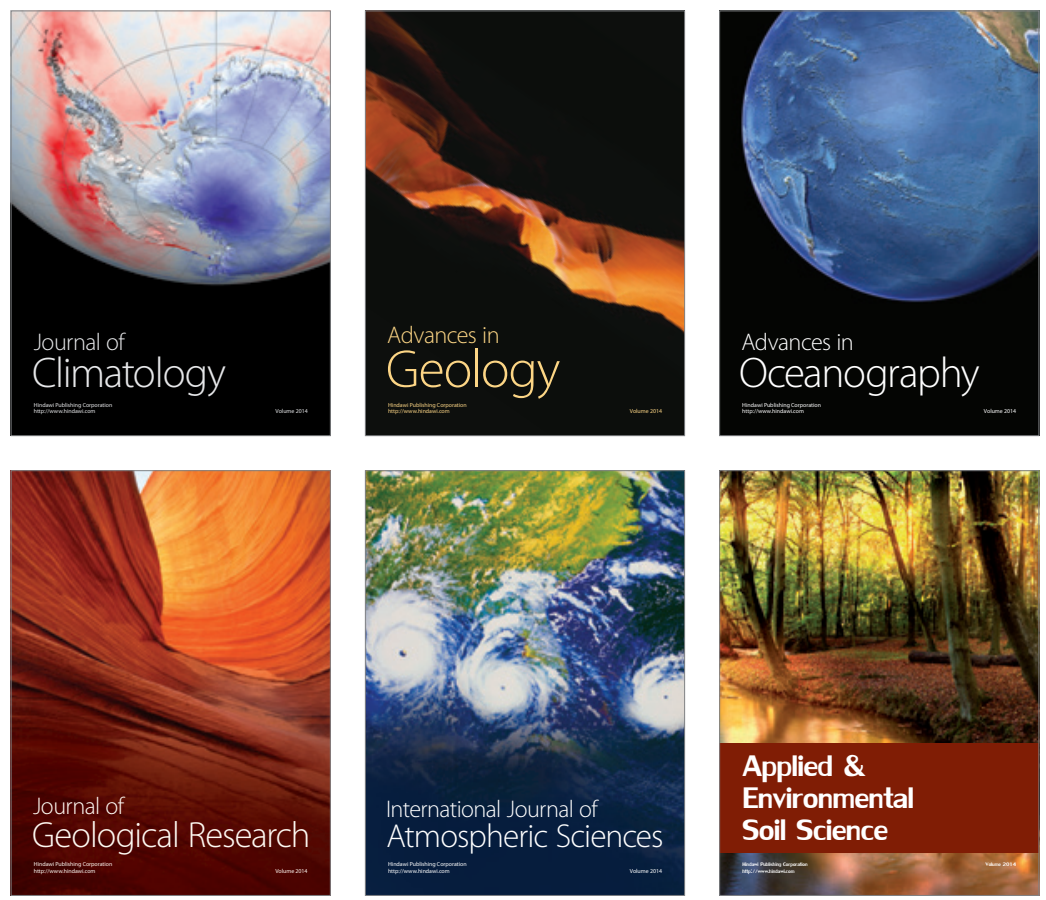
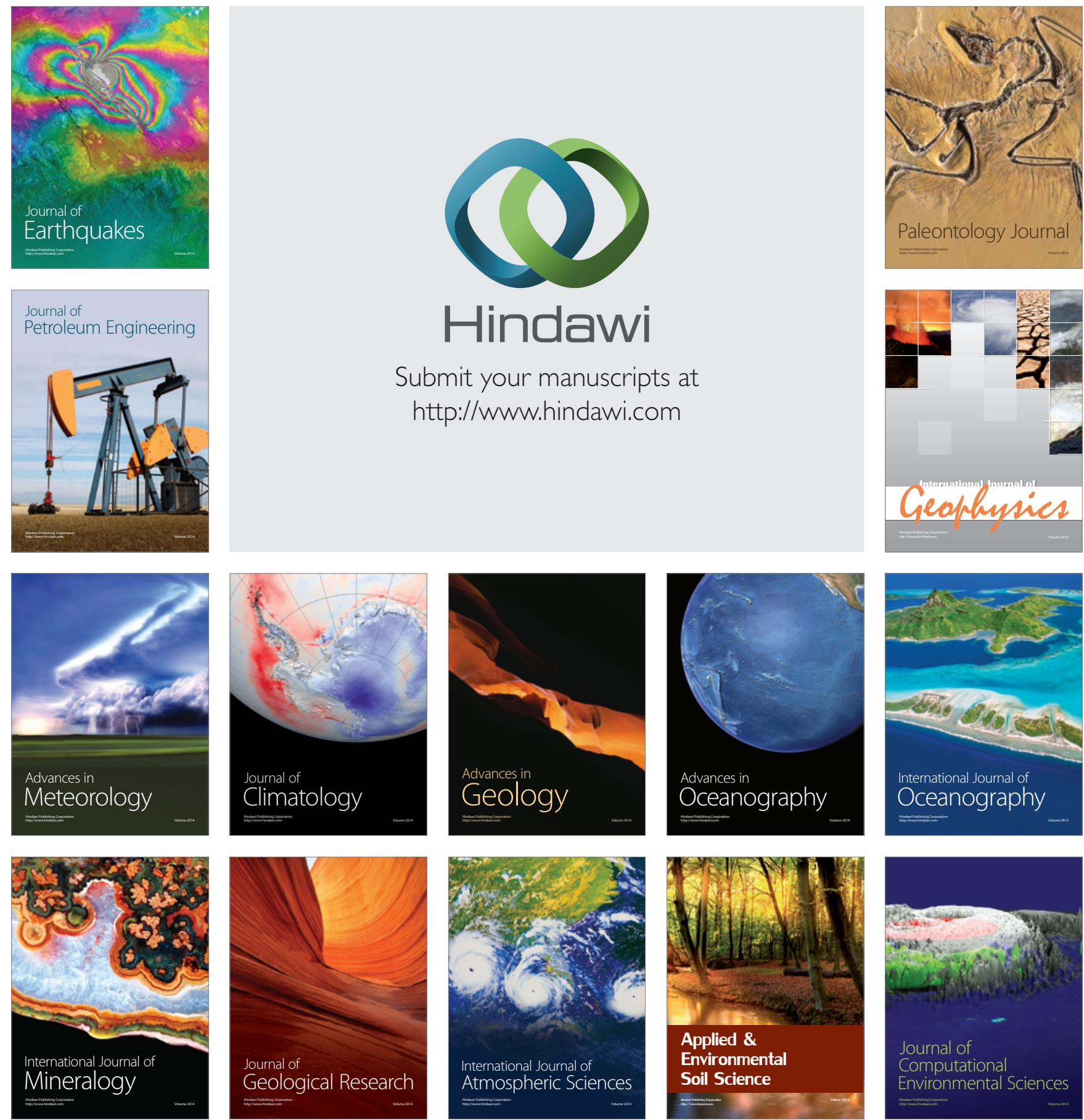